\title{
Extraction, rheological and textural analyses and grading of pectin from stem pith of banana
}

\author{
Rajendran Neravathu Sivan, \\ Balakrishnan Saraswathy Harikumaran Thampi
}

\author{
University of Calicut, Kerala, India
}

Keywords:

Banana

Pectin

Extraction

Rheology

Texture

Grading

\section{Article history:}

Received 20.09.2020

Received in revised

form 17.03.2021

Accepted 25.03.2021

\section{Corresponding}

author:

Dr. B.S.

Harikumaran Thampi

E-mail:

drhari@uoc.ac.in

DOI: $10.24263 / 2304-$

974X-2021-10-1-11

\section{Abstract}

Introduction. Purpose of the work - to identify suitable conditions for the extraction of pectin from stem pith of banana and to investigate how it affects rheological and textural properties of fruit jams.

Materials and methods. Stem pith of local banana cultivar. Pectin extracted using hot water acidified with sulfuric acid. Yield was studied and expressed as percentage of dried raw material used. Degree of methylation was studied using titration method, monomeric composition was studied using high performance anion exchange chromatography with pulsed amperometric detector. Effect of banana pectin upon flow behavior and texture profile of the pineapple jam prepared with it was studied using rheometer. The pectin was graded using modified line spread method.

Results and discussion. 27.91\% of yield was obtained. All independent variables were found to affect the yield to varying degrees. Temperature and $\mathrm{pH}$ were found to be the most important conditions affecting yield, while time of heating and SLR (time of heating and solid to liquid ratio) were also found to be affecting the yield, but to a lesser extent. The highest of the yield was at a SLR of $50, \mathrm{pH}$ of 1.5 , temperature of $82^{\circ} \mathrm{C}$ and a time of heating of 52.5 minutes.

Degree of methoxylation was found to be $62 \%$ with a composition similar to that of pectin from other sources reported by other workers.

Banana pectin was found to be affecting the rheological and textural properties of pineapple jam. Yield stress of pineapple prepared using banana pectin was found to be $113 \mathrm{~Pa}$, compared with $96 \mathrm{~Pa}$ for control. At the same time highest shear modulus for the test was $94 \mathrm{~Pa}$, against a value of $60 \mathrm{~Pa}$ for the control. While banana pectin was found to be affecting the strength of pineapple jam, more of it was required to achieve it compared with citrus pectin. More force was required to make the jam flow, indicating a higher yield stress compared with citrus pectin.

Textural properties of the jam were affected by the addition of banana pectin. Hardness was reduced from 6.18 for the control to 2.3 for the test while cohesiveness was reduced from 5.3 for control to 1.96 for test. At the time springiness was increased from 6.24 to 7.52 . Grade banana pectin was found to be 90.9 .

Conclusions. Stem pith of banana is a potential alternate raw material for the extraction of pectin and the pectin so extracted is suitable to use as a gelling agent in food materials. 


\section{Introduction}

Pectin is used as a thickening and gelling agent in food and other industries for a long period of time. Traditionally, it is obtained as a value-added product from agro-waste materials. As new pectin-containing food (and non-food) products are developed continuously, the demand for pectin increases throughout the world, making it necessary to identify new sources for its feasible large-scale extraction. (Arachchige et al., 2020), (Dimopoulou et al., 2019). The newly identified sources should be abundant and locally available at low-cost, should yield pectin with minimum or no damage to the environment, should give a reasonable yield per unit weight of the raw material and the extracted pectin should contribute significantly towards the flow behaviour and textural properties of food materials. The conditions affecting the yield need to be identified, in order to device a financially viable strategy for its large-scale extraction. Moreover, source - structureusability relationship need to be established (Ciriminna et al., 2019). This is especially important because the structure, and therefore the applications, of pectin greatly depend upon the sources from which it is extracted.

Banana is the most abundantly cultivated fruit in the world. After using the fruits of banana, most of the remaining parts of the cultivated plant are thrown away as waste. Natural calamities and pest infestation also lead to the loss of a large quantity of banana plants before harvesting. These wasted components in banana cultivation have been explored as a source of pectin recently. The authors of this article have shown that peel (N. S. Rajendran and B.S. Harikumaran Thampi, 2019) and underground stem (Rajendran and Harikumaran Thampi, 2021) of banana can be used as a viable source of pectin.

Stem pith of banana - the white part, enclosed by leaf sheaths, rising above the soil, terminating with flower and fruit bunch- has rarely been explored as a source of pectin, and there is no publication in this regard.

Therefore, in this work, we aim to substantiate the feasibility of using stem pith of banana as a source of pectin, and also to study the usefulness of the extracted pectin as a gelling agent in food industries.

\section{Materials and methods}

\section{Studied products}

Stem pith of Poovan (AAB) cultivar (local name) was collected from a local farm in Palakkad district, Kerala state of India. The plant used as raw material in this study is being described in "Cytotaxonomical Studies on Banana Cultivars", by P.K. Valsalakumari (Valsalakumari, 1984), Kerala Agricultural University, Kerala, India in 1984, as picture plate no. 16 , page no. 87-88).

\section{Extraction of pectin}

Fresh stem pith was washed with tap water, cut and pulverized, dried under sun to constant weight, powdered and packed until use. Measured quantities were transferred to particular volume of sulfuric acid-water mixture (Bouhennil et al., 2019) of particular pH, heated at pre-defined temperature for definite time period, cooled to room temperature, dust removed by centrifugation, $\mathrm{pH}$ raised to 6 using barium carbonate, pectin precipitated with double volume of isopropyl alcohol, vacuum dried and powdered.

Estimation of Degree of methyl esterification - The method provided in Food Chemicals Codex was used (Birch, 2003). 


\section{Analysis of monomeric composition}

Powdered pectin was hydrolysed with trifluoroacetic acid at $105^{\circ} \mathrm{C}$ for 5 hours, acid removed by evaporation, $10 \mu \mathrm{g}$ was injected in to high performance anion exchange chromatography (HPAEC) CarboPacPA-1 column (4mm x 250mm) with $100 \mathrm{mM}$ sodium hydroxide and sodium acetate gradient, equipped with pulsed amperometric detector (PAD). Dionex ICS-3000 was used for monomer analysis.

\section{Rheological analysis}

Preparation of pineapple jam: Ripe pineapple was purchased from local market, washed, chopped in to small pieces, pulverised and filtered through a $2 \mathrm{~mm}$ mesh to get the juice. $52 \mathrm{~g}$ of this juice was measured in to a vessel, 25g sucrose was added, boiled to a certain extent, powdered mixture of $1 \mathrm{~g}$ sucrose and $0.25 \mathrm{~g}$ of pectin was added, boiled again until a brix of $60 \%$ was reached, citric acid was added to bring the $\mathrm{pH}$ to 3.6 cooled to room temperature and packed (Hlaing, 2019).

Estimation of Yield stress of pineapple jam: Amplitude sweep curves of the above jams were obtained at $25^{\circ} \mathrm{C}, 11 \mathrm{~Hz}$ frequency, shear strain range 0.1 to 100 , with a Rheometer (Aanton Paar) model MCR 52, plate-plate method, with a $1 \mathrm{~mm}$ thickness of sample in between.

\section{Texture profile analysis}

The above pineapple jam was placed on the lower plate of Universal Testing Machine, Lloyd, LR-5K model, cylindrical probe $-80 \mathrm{~mm}$, load cell of $50 \mathrm{~N}$, speed of $50 \mathrm{~mm} / \mathrm{min}$, at $25^{\circ} \mathrm{C}$ and the values were processed with NEXYGENPlus data Analysis Software provided by the manufacturer. Gumminess was calculated as the product of cohesiveness and hardness while chewiness was calculated as the product of springiness and gumminess (Hussain et al., 2020).

\section{Grading}

The consistency of a gel prepared using pectin, sucrose and water was measured and compared with that of a gel made using 150 grade, standard citrus pectin. $\mathrm{pH}$ of the gel was adjusted using citric acid and sodium citrate. The process was repeated by adjusting the concentration of pectin, until a gel with consistency matching with that of gel made with citrus pectin was obtained. The ratio of grams of sucrose to that of banana pectin used for making this gel was expressed as the grade of pectin.

Preparation of gel: Measured amounts of sucrose and water were boiled, pectin was powdered with sucrose and added, $1 \mathrm{ml} 25 \%$ citric acid and $2 \mathrm{ml} 12.5 \%$ sodium citrate were added with continuous boiling, removed from flame, $4 \mathrm{ml}$ of $25 \%$ citric acid and $1 \mathrm{ml}$ of $12.5 \%$ sodium citrate were added, cooled to room temperature overnight, then consistency was compared with a gel made in the same manner using standard citrus pectin (Ranganna S., 1986).

Measurement of consistency of pectin-sucrose gel using modified Line-Spread method: $3.0 \mathrm{ml}$ of the gel was poured in to a horizontal glass plate at room temperature, and allowed to spread, length of the gel was measured at the widest part using a scale after three minutes (Kim et al., 2018). This process was repeated until similar values were obtained for gels prepared with banana pectin and standard pectin. Grade of banana pectin is determined using its concentration in this gel. 


\section{Statistical analysis}

Data were analysed using t-test, two sample, assuming unequal variance, (MS Excel 2017), $\mathrm{p} \leq 0.05$. Results were used to assess the impact of changing conditions of extraction upon yield of pectin. The same test was used to analyse the effect of banana pectin upon rheological and textural properties of the pineapple jam.

\section{Results and discussion}

\section{Yield}

The highest yield was $27.9 \%$. Temperature and $\mathrm{pH}$ were found to be the most important conditions affecting yield while time of heating and SLR were also found to be affecting the yield, but to a lesser extent. These findings are in agreement with data published by other workers (Wang et al., 2016).

\section{Effect of temperature on yield}

Table 1 shows the effect of increase in temperature upon yield.

Table 1

Effect of temperature of extraction upon yield of pectin from stem pith of Poovan cultivar of banana

\begin{tabular}{|l|c|c|c|c|c|c|}
\hline \multirow{2}{*}{ Pairs } & SET & SLR & $\mathbf{p H}$ & $\begin{array}{c}\text { Time, } \\
\text { minutes }\end{array}$ & $\begin{array}{c}\text { Temperature, } \\
{ }^{\circ} \mathbf{C}\end{array}$ & $\begin{array}{c}\text { Yield, } \\
(\%)\end{array}$ \\
\hline \multirow{2}{*}{ Pair 1 } & A & 30 & 1.5 & 52.5 & 54 & $1.29 \pm 0.24$ \\
\cline { 2 - 7 } & B & 30 & 1.5 & 52.5 & 82 & $14.20 \pm 1.16^{\mathrm{A}}$ \\
\hline \multirow{2}{*}{ Pair 2 } & $\mathrm{A}$ & 30 & 1.5 & 97.5 & 54 & $4.55 \pm 0.64$ \\
\cline { 2 - 7 } & $\mathrm{B}$ & 30 & 1.5 & 97.5 & 82 & $26.35 \pm 2.50^{\mathrm{A}}$ \\
\hline \multirow{2}{*}{ Pair 3 } & $\mathrm{A}$ & 30 & 2.5 & 52.5 & 54 & $2.51 \pm 0.13$ \\
\cline { 2 - 7 } & $\mathrm{B}$ & 30 & 2.5 & 52.5 & 82 & $3.98 \pm 0.52^{\mathrm{A}}$ \\
\hline \multirow{2}{*}{ Pair 4 } & $\mathrm{A}$ & 30 & 2.5 & 97.5 & 54 & $1.93 \pm 0.23$ \\
\cline { 2 - 7 } & $\mathrm{B}$ & 30 & 2.5 & 97.5 & 82 & $2.78 \pm 0.34$ \\
\hline \multirow{2}{*}{ Pair 5 } & $\mathrm{A}$ & 40 & 2.0 & 75.0 & 68 & $8.34 \pm 0.73$ \\
\cline { 2 - 7 } & $\mathrm{B}$ & 40 & 2.0 & 75.0 & 96 & $18.02 \pm 1.87^{\mathrm{A}}$ \\
\hline \multirow{2}{*}{ Pair 6 } & $\mathrm{A}$ & 50 & 1.5 & 52.5 & 54 & $2.44 \pm 0.49$ \\
\cline { 2 - 7 } & $\mathrm{B}$ & 50 & 1.5 & 52.5 & 82 & $27.91 \pm 3.22^{\mathrm{A}}$ \\
\hline \multirow{2}{*}{ Pair 7 } & $\mathrm{A}$ & 50 & 1.5 & 97.5 & 54 & $15.17 \pm 2.06$ \\
\cline { 2 - 7 } & $\mathrm{B}$ & 50 & 1.5 & 97.5 & 82 & $26.52 \pm 2.88^{\mathrm{A}}$ \\
\hline \multirow{2}{*}{ Pair 8 } & $\mathrm{A}$ & 50 & 2.5 & 97.5 & 54 & $1.42 \pm 0.23$ \\
\cline { 2 - 7 } & $\mathrm{B}$ & 50 & 2.5 & 97.5 & 82 & $5.54 \pm 0.84^{\mathrm{A}}$ \\
\hline \multirow{2}{*}{ Pair 9 } & $\mathrm{A}$ & 50 & 2.5 & 52.5 & 54 & $1.81 \pm 0.18$ \\
\cline { 2 - 7 } & $\mathrm{B}$ & 50 & 2.5 & 52.5 & 82 & $3.95 \pm 0.38^{\mathrm{A}}$ \\
\hline
\end{tabular}

*Values of yield are average of six independent analyses \pm SEM.

Set A in each pair is at a lower temperature, while set B is at a higher temperature. Superscript A against the value of yield indicates that the particular value of yield is significantly different from that of set A of the same pair. 
Temperature was found to be an important factor in deciding yield (Chen et al., 2021). It is found that in most of the cases, yield significantly increased upon increase in temperature, probably due to the increased penetration of the cell wall material by the extractant liquid at the higher temperature (Wang et al., 2016).

\section{Effect of pH upon yield}

Table 2 shows the effect of increasing $\mathrm{pH}$ upon yield of pectin. It is evident that, in most of the cases, increase in $\mathrm{pH}$ resulted in decreased yield. Thus, it may be concluded that, as a general rule, increased concentration of acid favors penetration of the extractant mineral acid solution in to the cell wall matrix of the raw material, releasing more pectin (Hlaing, 2019).

Effect of pH of extraction upon yield of pectin from stem pith of Poovan cultivar of banana

Table 2

\begin{tabular}{|l|c|c|c|c|c|c|}
\hline \multirow{2}{*}{ Pairs } & SET & SLR & $\begin{array}{c}\text { Time, } \\
\text { minutes }\end{array}$ & $\begin{array}{c}\text { Temperature, } \\
{ }^{\circ} \mathbf{C}\end{array}$ & $\mathbf{p H}$ & $\begin{array}{c}\text { Yield, } \\
(\mathbf{\%})\end{array}$ \\
\hline \multirow{2}{*}{ Pair 1 } & $\mathrm{A}$ & 30 & 52.5 & 54 & 1.5 & $1.29 \pm 0.24$ \\
\cline { 2 - 7 } & $\mathrm{B}$ & 30 & 52.5 & 54 & 2.5 & $2.51 \pm 0.13^{\mathrm{A}}$ \\
\hline \multirow{2}{*}{ Pair 2 } & $\mathrm{A}$ & 30 & 52.5 & 82 & 1.5 & $14.20 \pm 1.16$ \\
\cline { 2 - 7 } & $\mathrm{B}$ & 30 & 52.5 & 82 & 2.5 & $3.98 \pm 0.52^{\mathrm{A}}$ \\
\hline \multirow{2}{*}{ Pair 3 } & $\mathrm{A}$ & 30 & 97.5 & 54 & 1.5 & $4.55 \pm 0.64$ \\
\cline { 2 - 7 } & $\mathrm{B}$ & 30 & 97.5 & 54 & 2.5 & $1.93 \pm 0.23^{\mathrm{A}}$ \\
\hline \multirow{2}{*}{ Pair 4 } & $\mathrm{A}$ & 30 & 97.5 & 82 & 1.5 & $26.35 \pm 2.50$ \\
\cline { 2 - 7 } & $\mathrm{B}$ & 30 & 97.5 & 82 & 2.5 & $2.78 \pm 0.34^{\mathrm{A}}$ \\
\hline \multirow{2}{*}{ Pair 5 } & $\mathrm{A}$ & 40 & 75.0 & 68 & 2 & $8.34 \pm 0.73$ \\
\cline { 2 - 7 } & $\mathrm{B}$ & 40 & 75.0 & 68 & 3 & $3.35 \pm 0.47^{\mathrm{A}}$ \\
\hline \multirow{2}{*}{ Pair 6 } & $\mathrm{A}$ & 50 & 52.5 & 54 & 1.5 & $2.44 \pm 0.49$ \\
\cline { 2 - 7 } & $\mathrm{B}$ & 50 & 52.5 & 54 & 2.5 & $1.81 \pm 0.18$ \\
\hline \multirow{2}{*}{ Pair 7 } & $\mathrm{A}$ & 50 & 52.5 & 82 & 1.5 & $27.91 \pm 3.22$ \\
\cline { 2 - 7 } & $\mathrm{B}$ & 50 & 52.5 & 82 & 2.5 & $3.95 \pm 0.38^{\mathrm{A}}$ \\
\hline \multirow{2}{*}{ Pair 8 } & $\mathrm{A}$ & 50 & 97.5 & 54 & 1.5 & $15.17 \pm 2.06$ \\
\cline { 2 - 7 } & $\mathrm{B}$ & 50 & 97.5 & 54 & 2.5 & $1.42 \pm 0.23^{\mathrm{A}}$ \\
\hline \multirow{2}{*}{ Pair 9 } & $\mathrm{A}$ & 50 & 97.5 & 82 & 1.5 & $26.52 \pm 2.88$ \\
\cline { 2 - 7 } & $\mathrm{B}$ & 50 & 97.5 & 82 & 2.5 & $5.54 \pm 0.84^{\mathrm{A}}$ \\
\hline
\end{tabular}

* Values of yield are average of six independent analyses \pm SEM.

Set $\mathrm{A}$ in each pair is at a lower $\mathrm{pH}$, while set $\mathrm{B}$ is at a higher $\mathrm{pH}$.

Superscript A against the value of yield indicates that the particular value of yield is significantly different from that of set A of the same pair.

\section{Effect of time period of heating upon yield}

A quick look at the Table 3 indicates that more pectin was released from the raw material when it was heated for longer duration as was demonstrated by other workers (Fakayode and Abobi, 2018). This might be due to the more effective penetration of the extractant solution in to the deeper layers of the cell wall, leading to breakdown of chemical bonds both within pectin and also between pectin and other molecules in it (Li et al., 2019). 
Generally, in most of the cases, change in yield upon increased time of heating was statistically not significant, under the experimental conditions used for this study.

Table 3

Effect of time of heating upon yield of pectin from stem pith of Poovan cultivar of banana

\begin{tabular}{|c|c|c|c|c|c|c|}
\hline Pairs & SET & SLR & pH & $\begin{array}{c}\text { Time, } \\
\text { minutes }\end{array}$ & $\begin{array}{c}\text { Temperature, } \\
{ }^{\circ} \mathrm{C}\end{array}$ & $\begin{array}{c}\text { Yield, } \\
(\%)\end{array}$ \\
\hline \multirow[b]{2}{*}{ Pair 1} & A & 30 & 1.5 & 54 & 52.5 & $1.29 \pm 0.24$ \\
\hline & $\mathrm{B}$ & 30 & 1.5 & 54 & 97.5 & $4.55 \pm 0.64^{\mathrm{A}}$ \\
\hline \multirow[b]{2}{*}{ Pair 2} & $\mathrm{~A}$ & 30 & 1.5 & 82 & 52.5 & $14.20 \pm 1.16$ \\
\hline & $\mathrm{B}$ & 30 & 1.5 & 82 & 97.5 & $26.35 \pm 2.50^{\mathrm{A}}$ \\
\hline \multirow[b]{2}{*}{ Pair 3} & $\mathrm{~A}$ & 30 & 2.5 & 54 & 52.5 & $2.51 \pm 0.13$ \\
\hline & $\mathrm{B}$ & 30 & 2.5 & 54 & 97.5 & $1.93 \pm 0.23$ \\
\hline \multirow[b]{2}{*}{ Pair 4} & $\mathrm{~A}$ & 30 & 2.5 & 82 & 52.5 & $3.98 \pm 0.52$ \\
\hline & $\mathrm{B}$ & 30 & 2.5 & 82 & 97.5 & $2.78 \pm 0.34$ \\
\hline \multirow[b]{2}{*}{ Pair 5} & $\mathrm{~A}$ & 40 & 2.0 & 68 & 75 & $8.34 \pm 0.73$ \\
\hline & $\mathrm{B}$ & 40 & 2.0 & 68 & 120 & $8.61 \pm 0.64$ \\
\hline \multirow[b]{2}{*}{ Pair 6} & $\mathrm{~A}$ & 50 & 1.5 & 54 & 52.5 & $2.44 \pm 0.49$ \\
\hline & $\mathrm{B}$ & 50 & 1.5 & 54 & 97.5 & $15.17 \pm 2.06^{\mathrm{A}}$ \\
\hline \multirow[b]{2}{*}{ Pair 7} & $\mathrm{~A}$ & 50 & 1.5 & 82 & 52.5 & $27.91 \pm 3.22$ \\
\hline & $\mathrm{B}$ & 50 & 1.5 & 82 & 97.5 & $26.52 \pm 2.88$ \\
\hline \multirow[b]{2}{*}{ Pair 8} & $\mathrm{~A}$ & 50 & 2.5 & 54 & 52.5 & $1.81 \pm 0.18$ \\
\hline & $\mathrm{B}$ & 50 & 2.5 & 54 & 97.5 & $1.42 \pm 0.23$ \\
\hline \multirow[b]{2}{*}{ Pair 9} & $\mathrm{~A}$ & 50 & 2.5 & 82 & 52.5 & $3.95 \pm 0.38$ \\
\hline & $\mathrm{B}$ & 50 & 2.5 & 82 & 97.5 & $5.54 \pm 0.84$ \\
\hline
\end{tabular}

$*$ Values of yield are average of six independent analyses \pm SEM.

Set A in each pair is at a lower time period, compared with set B.

Superscript A against the value of yield indicates that the particular value of yield is significantly different from that of set A of the same pair.

\section{Effect of solid to liquid ratio (SLR) upon yield of pectin}

Results are given in Table 4. It is evident that in half of the experiments increase in SLR resulted in a statistically significant change in yield. In many of the cases, increased SLR resulted in increased yield, because:

a. Increased dilution of the solution stabilised the released pectin, thereby helping releasing of more bound pectin from cell wall materials;

b. Of the increased penetration of extractant liquid in to the biomass to release more pectin. 
Table 4

Effect of SLR upon yield of pectin from stem pith of Poovan cultivar of banana

\begin{tabular}{|c|c|c|c|c|c|c|}
\hline Pairs & SET & pH & $\begin{array}{c}\text { Time, } \\
\text { minutes }\end{array}$ & $\begin{array}{c}\text { Temperature, } \\
{ }^{\circ} \mathrm{C} \\
\end{array}$ & SLR & $\begin{array}{c}\text { Yield, } \\
(\%)\end{array}$ \\
\hline \multirow[b]{2}{*}{ Pair 1} & A & 1.5 & 52.5 & 54 & 30 & $1.29 \pm 0.24$ \\
\hline & $\mathrm{B}$ & 1.5 & 52.5 & 54 & 50 & $2.44 \pm 0.49$ \\
\hline \multirow[b]{2}{*}{ Pair 2} & $\mathrm{~A}$ & 1.5 & 52.5 & 82 & 30 & $14.20 \pm 1.16$ \\
\hline & $\mathrm{B}$ & 1.5 & 52.5 & 82 & 50 & $27.91 \pm 3.22^{\mathrm{A}}$ \\
\hline \multirow[b]{2}{*}{ Pair 3} & $\mathrm{~A}$ & 1.5 & 97.5 & 54 & 30 & $4.55 \pm 0.64$ \\
\hline & $\mathrm{B}$ & 1.5 & 97.5 & 54 & 50 & $15.17 \pm 2.06^{\mathrm{A}}$ \\
\hline \multirow[b]{2}{*}{ Pair 4} & $\mathrm{~A}$ & 1.5 & 97.5 & 82 & 30 & $26.35 \pm 2.50$ \\
\hline & $\mathrm{B}$ & 1.5 & 97.5 & 82 & 50 & $26.52 \pm 2.88$ \\
\hline \multirow[b]{2}{*}{ Pair 5} & $\mathrm{~A}$ & 2 & 75.0 & 68 & 40 & $8.34 \pm 0.73$ \\
\hline & $\mathrm{B}$ & 2 & 75.0 & 68 & 60 & $3.87 \pm 0.56^{\mathrm{A}}$ \\
\hline \multirow[b]{2}{*}{ Pair 6} & $\mathrm{~A}$ & 2.5 & 52.5 & 54 & 30 & $2.51 \pm 0.13$ \\
\hline & $\mathrm{B}$ & 2.5 & 52.5 & 54 & 50 & $1.81 \pm 0.18^{\mathrm{A}}$ \\
\hline \multirow[b]{2}{*}{ Pair 7} & $\mathrm{~A}$ & 2.5 & 52.5 & 82 & 30 & $3.98 \pm 0.52$ \\
\hline & $\mathrm{B}$ & 2.5 & 52.5 & 82 & 50 & $3.95 \pm 0.38$ \\
\hline \multirow[b]{2}{*}{ Pair 8} & $\mathrm{~A}$ & 2.5 & 97.5 & 54 & 30 & $1.93 \pm 0.23$ \\
\hline & $\mathrm{B}$ & 2.5 & 97.5 & 54 & 50 & $1.42 \pm 0.23$ \\
\hline \multirow[b]{2}{*}{ Pair 9} & $\mathrm{~A}$ & 2.5 & 97.5 & 82 & 30 & $2.78 \pm 0.34$ \\
\hline & B & 2.5 & 97.5 & 82 & 50 & $5.54 \pm 0.84^{\mathrm{A}}$ \\
\hline
\end{tabular}

*Values of yield are average of six independent analyses \pm SEM.

Set A in each pair is at a lower SLR, compared with set B.

Superscript A against the value of yield indicates that the particular value of yield is significantly different from that of set $\mathrm{A}$ of the same pair

\section{Degree of esterification (D.E.)}

The D.E. was found to be $62 \%$, indicating that banana pectin was a high methyl pectin. This is comparable with pectin from other sources (Li et al., 2019).

\section{Monomeric composition}

The following monomers (Table 5) were identified from the pectin extracted from stem pith of Poovan cultivar. It is similar to the results published by other workers from other raw materials (Sabater et al., 2020). 
Table 5

Types and quantity of monosaccharides present in $10 \mu \mathrm{g}$ of hydrolysed pectin obtained from stem pith of Poovan cultivar of banana

\begin{tabular}{|c|l|c|}
\hline Sl. No. & Name of monomer & Quantity $(\boldsymbol{\mu g})$ \\
\hline 1 & Fucose & 0.024 \\
\hline 2 & Rhamnose & 0.136 \\
\hline 3 & Arabinose & 0.128 \\
\hline 4 & Glucosamine & 0.004 \\
\hline 5 & Galactose & 0.266 \\
\hline 6 & Glucose & 0.428 \\
\hline 7 & Mannose & 0.23 \\
\hline 8 & Xylose & 0.056 \\
\hline 9 & Galacturonic acid & 0.075 \\
\hline 10 & Glucuronic acid & 0.064 \\
\hline
\end{tabular}

\section{Rheological analysis}

Comparison of gelling ability of different types of pectin is shown in Table 6 . The pectin samples extracted were non-Newtonian and exhibited shear thinning behavior and is consistent with data from other workers ( $\mathrm{Li}$ et al., 2019). Shear modulus, a measure of the strength of the material, was found to be increased upon addition of pectin and is comparable with pectin from other sources (Koubala et al., 2009). However, more of the banana pectin was required to bring up the shear modulus up to that of citrus pectin. At the same time, yield stress, the stress beyond which the material begins to flow, was much more for banana pectin than for citrus pectin. Thus more force need to applied to induce flow, under the given set of conditions (Dinkgreve et al., 2016). These findings indicate that flow behavior of food gels may be modified by careful use of banana pectin, as was reported earlier by workers using pectin from other sources (Norziah et al., 2000).

Table 6

Comparison effect of pectin from different sources upon flow behaviour of pineapple jam

\begin{tabular}{|l|l|l|}
\hline \multirow{2}{*}{ Experiment } & Yield stress & Highest shear modulus \\
\cline { 2 - 3 } & Average & Average \\
\hline $\mathrm{A}-$ Control & $96.48 \pm 2.29$ & $60.31 \pm 1.43$ \\
\hline $\mathrm{B}-$ Std. & $63.62 \pm 1.51$ & $81.91 \pm 1.94$ \\
\hline $\mathrm{C}-$ Test & $113.21 \pm 2.68^{\mathrm{A}, \mathrm{B}}$ & $93.97 \pm 2.23^{\mathrm{A}, \mathrm{B}}$ \\
\hline
\end{tabular}

*The values are averages of six independent analyses \pm SEM. $p \leq 0.05$.

Superscripts A and B against the values of test indicate that the values are statistically significant compared with control (A) and Std (B).

Control contained no pectin, Std. contained $0.25 \mathrm{~g}$ of citrus pectin while Test contained $0.25 \mathrm{~g}$ of banana pectin. 


\section{Texture profile analysis}

Textural properties of the pineapple jam prepared using pectin from stem pith of Poovan cultivar of banana are shown and compared with standard citrus pectin in Table 7.

Texture profile analysis of pineapple jam prepared using pectin

Table 7

\begin{tabular}{|l|l|l|}
\hline \multirow{4}{*}{ Hardness1 (N) } & A - Control & $6.18 \times 10^{-1} \pm 1.21 \times 10^{-2}$ \\
\cline { 2 - 3 } & $\mathrm{B}-$ Std & $11.71 \pm 2.23 \times 10^{-1}$ \\
\cline { 2 - 3 } & $\mathrm{C}-$ Test & $2.3 \pm 4.46 \times 10^{-2 \mathrm{~A}, \mathrm{~B}}$ \\
\hline \multirow{4}{*}{ Hardness2 (N) } & $\mathrm{A}-$ Control & $5.31 \times 10^{-1} \pm 1.03 \times 10^{-2}$ \\
\cline { 2 - 3 } & $\mathrm{B}-$ Std & $9.2 \pm 1.78 \times 10^{-1}$ \\
\cline { 2 - 3 } & $\mathrm{C}-$ Test & $1.96 \pm 3.8 \times 10^{-2 \mathrm{~A}, \mathrm{~B}}$ \\
\hline \multirow{4}{*}{ Springiness (mm) } & $\mathrm{A}-$ Control & $7.68 \times 10^{-1} \pm 1.49 \times 10^{-2}$ \\
\cline { 2 - 3 } & $\mathrm{B}-$ Std & $5.0 \times 10^{-1} \pm 9.7 \times 10^{-3}$ \\
\hline & $\mathrm{C}-$ Test & $7.23 \times 10^{-1} \pm 1.4 \times 10^{-2 \mathrm{~B}}$ \\
\hline \multirow{4}{*}{ Gumminess (kgf) } & $\mathrm{A}-$ Control & $6.24 \pm 1.22 \times 10^{-1}$ \\
\cline { 2 - 3 } & $\mathrm{B}-$ Std & $7.25 \pm 1.42 \times 10^{-1}$ \\
\cline { 2 - 3 } & $\mathrm{C}-$ Test & $7.52 \pm 1.45 \times 10^{-1 \mathrm{~A}}$ \\
\hline \multirow{3}{*}{ Chewiness (kgf.mm) } & $\mathrm{A}-$ Control & $4.84 \times 10^{-2} \pm 9.42 \times 10^{-4}$ \\
\cline { 2 - 3 } & $\mathrm{B}-$ Std & $5.97 \times 10^{-1} \pm 1.15 \times 10^{-2}$ \\
\cline { 2 - 3 } & $\mathrm{C}-$ Test & $1.7 \times 10^{-1} \pm 3.27 \times 10^{-3 \mathrm{~A}, \mathrm{~B}}$ \\
\hline & $\mathrm{A}-$ Control & $3.02 \times 10^{-1} \pm 5.77 \times 10^{-3}$ \\
\cline { 2 - 3 } & $\mathrm{B}-$ Std & $4.33 \pm 8.39 \times 10^{-2}$ \\
\cline { 2 - 3 } & $\mathrm{C}-$ Test & $1.28 \pm 2.49 \times 10^{-2 \mathrm{~A}, \mathrm{~B}}$ \\
\hline \multirow{3}{*}{ Adhesiveness (kgf.mm) } & $\mathrm{A}-$ Control & $2.4 \times 10^{-3} \pm 4.61 \times 10^{-5}$ \\
\cline { 2 - 3 } & $\mathrm{B}-$ Std & $6.31 \times 10^{-2} \pm 1.22 \times 10^{-3}$ \\
\cline { 2 - 3 } & $\mathrm{C}-$ Test & $1.41 \times 10^{-2} \pm 2.76 \times 10^{-4 \mathrm{~A}, \mathrm{~B}}$ \\
\hline
\end{tabular}

Values are averages of six independent analyses \pm SEM. $p \leq 0.05$.

Superscripts A and B against the value of test indicate that the particular value is statistically significant compared with control and standard respectively.

"Control" contains no added pectin, 'Std' contains standard citrus pectin while

"Test" contains pectin extracted from stem pith of Poovan cultivar of banana.

Analysis of the textural profile indicates that all textural properties were influenced by banana pectin. Therefore, a different set of textural properties may be achieved for the food material, by replacing citrus pectin with banana pectin (Cruz et al., 2019). Hardness is the most important textural property of food materials, having a direct role in consumer satisfaction and marketability (Monalisa et al., 2020). Hardness of jam increased upon the addition of banana pectin, but the magnitude of increase was less than that of citrus pectin. It indicates that more force is required to compress the jam containing banana pectin compared with the control, but less force compared with standard (Di Monaco et al., 2008). This is an important finding as it helps to prepare food for people with difficulty in mastication and deglutition (Nishinari et al., 2019). By adjusting the concentration of banana pectin, food materials of required hardness and other textural properties may be prepared (Anuar and 
Salleh, 2019). Cohesiveness, a measure of the strength of chemical bonds in the jam under study, was brought down upon the addition of banana pectin but not as much as citrus pectin. This means that the energy required for successive rounds of chewing decreases more than that for the control and this concept is helpful while formulating food for the elderly (Nishinari et al., 2016). A chewiness - product of springiness, cohesiveness and hardness more than control, indicates that more energy is required to chew the jam prepared with banana pectin, until it can be swallowed.

\section{Grading}

The grade of banana pectin was found to be 90.9 , while many authors have reported 150 grade pectin from other sources (Maskey et al., 2018). This means that more of the banana pectin is required to bring about the same consistency of the gel, compared with citrus pectin. However, this cannot be observed as a demerit of banana pectin, because more of it can be obtained from the waste produced from one banana plant and also because, of the huge quantity of banana plants being cultivated globally (FAO, 2019).

\section{Conclusion}

1. Pectin obtained from stem pith of Poovan cultivar of banana is an effective alternative plant-derived gelling agent useful in food industries.

2. Temperature and $\mathrm{pH}$ of extraction were found to determine the yield predominantly, even though time of heating and SLR also were important parameters.

3. Banana pectin has a monomeric composition similar to that of pectin from other sources.

4. Its rheological and textural properties also were suitable to enable its use for preparation of fruit jams.

5. Grade of the pectin was found to be less than that of citrus pectin.

Acknowledgements. The authors would like to extend their gratitude to CSIR - CFTRI, Mysore, India (Rheology and Textural Profile Analysis) and Biomedical Research Facility, California University, San Diego, USA (HPAEC - PAD) for providing their laboratory facilities for this work.

\section{References}

Anuar N.A. and Salleh R.M. (2019), Development of fruit jam from Averrhoa bilimbi L., Journal of Food Processing and Preservation 43(4), pp. e13904.

Arachchige M.P.M., Mu T. and Ma M. (2020), Structural, physicochemical and emulsifying properties of sweet potato pectin treated by high hydrostatic pressure and/or pectinase: a comparative study, Journal of the Science of Food and Agriculture, 100(13), pp. 4911-4920.

Birch G. (2003), Food Chemicals Codex, 59(1), pp. 179-180 
Bouhenni H., Doukani K., Şekeroğlu N. et al. (2019), Comparative study on chemical composition and antibacterial activity of fenugreek (Trigonella Foenum graecum L.), and cumin (Cuminum cyminum L.), seeds, Ukrainian Food Journal, 8(4), pp. 755-767.

Chen J., Cheng H., Zhi Z. et al. (2021), Extraction temperature is a decisive factor for the properties of pectin, Food Hydrocolloids, 112, pp. 106160

Ciriminna R., Fidalgo A., Avellone G. et al. (2019), Economic and technical feasibility of betanin and pectin extraction from opuntia ficus-indica peel via microwave-assisted hydrodiffusion, ACS Omega 4(7),. American Chemical Society, pp. 12121-12124.

Cruz V.A., Gonçalves C.A.A., Masson G.A., et al. (2019), Manufacturing of Formosa papaya (Carica papaya L.), jam containing different concentrations of dehydrated papaya seed flour, International Food Research Journal, 26(3), pp. 849-857

Di Monaco R., Cavella S. Masi P. (2008), Predicting Sensory Cohesiveness, Hardness and Springiness of Solid Foods from Instrumental Measurements, Journal of Texture Studies, 39(2), pp. 129-149.

Dimopoulou M., Alba K., Campbell G. et al. (2019), Pectin recovery and characterization from lemon juice waste streams, Journal of the Science of Food and Agriculture, 99 (14), pp. 6191-6198.

Dinkgreve M., Paredes J., Denn M.M. et al. (2016), On different ways of measuring "the" yield stress, Journal of Non-Newtonian Fluid Mechanics, 238, pp. 233-241.

Fakayode O.A. and Abobi K.E. (2018), Optimization of oil and pectin extraction from orange (Citrus sinensis), peels: a response surface approach, Journal of Analytical Science and Technology, 9(20), pp. 1-16.

FAO (2019), Banana Facts and Figures. In: FAOSTAT. United Nations Organisations: FAO.

Hlaing S.S. (2019), Extraction of Pectin Powders from Guava and Apple And their Applications in Jam Making Processes, Yadanabon University Research Journal, 10 (1), pp. $1-11$.

Hussain S., Mohamed A.A., Alamri M.S. et al. (2020), Wheat-millet flour cookies: Physical, textural, sensory attributes and antioxidant potential, Food Science and Technology International, 26(4), pp. 311-320.

Kim Y-H., Jeong G.Y. and Yoo B. (2018), Comparative study of IDDSI flow test and line-spread test of thickened water prepared with different dysphagia thickeners, Journal of Texture Studies, 49(6), pp. 653-658.

Koubala B.B., Kansci G., Garnier C. et al. (2009), Rheological and high gelling properties of mango (Mangifera indica), and ambarella (Spondias cytherea), peel pectins, International Journal of Food Science and Technology, 44. pp. 1809-1817.

Li W., Fan Z., Wu Y. et al. (2019), Eco-friendly extraction and physicochemical properties of pectin from jackfruit peel waste with subcritical water, Journal of the Science of Food and Agriculture, 99(12), pp. 5283-5292.

Maskey B., Dhakal D., Pradhananga M. et al. (2018), Extraction and process optimization of bael fruit pectin, Food Science and Nutrition, 6(7), pp. 1927-1932.

Monalisa K., Bhuiyan J.A., Islam M.Z., et al. (2020), Boiling-induced changes on physicochemical, bioactive compounds, color, and texture properties of pumpkin (Cucurbita maxima), Food Science and Technology International , 26 (4), pp. 333-343.

Rajendran N. S. and Harikumaran Thampi N. S. (2019), Extraction and Characterisation of Pectin from Banana Peel, Carpathian Journal of Food Science and Technology, 11(4), pp. 45-63.

Nishinari K., Takemasa M., Brenner T. et al. (2016), The Food Colloid Principle in the Design of Elderly Food, Journal of Texture Studies, 47(4), pp. 284-312. 
Nishinari K., Turcanu M., Nakauma M. et al. (2019), Role of fluid cohesiveness in safe swallowing. npj Science of Food. Nature Research, 3(5), pp. 1-13

Norziah M.H., Fang E.O. and Karim A.A. (2000), Extraction and Characterisation of Pectin From Pomelo Fruit Peels, Gums and Stabilisers for the Food Industry, 10, pp. 27-36.

Rajendran and Harikumaran Thampi (2021), Pectin - Extraction from underground stem of banana and its structural, rheological , and textural analyses and grading, Journal of Food Processing and Preservation, pp. 1-10.

Ranganna S. (1986), Handbook of Analysis and Quality Control for Fruit and Vegetable Products (2nd Ed), New Delhi.

Sabater C., Sabater V., Olano A., et al. (2020), Ultrasound-assisted extraction of pectin from artichoke by-products. An artificial neural network approach to pectin characterisation, Food Hydrocolloids, 98, pp. 105238

Valsalakumari P.K. (1984), Cytotaxonomical Studies on Banana Cultivars, Kerala Agricultural University.

Wang M., Huang B., Fan C. et al. (2016), Characterization and functional properties of mango peel pectin extracted by ultrasound assisted citric acid, International Journal of Biological Macromolecules, 91, pp. 794-803. 